\title{
Novel curcumin analogue IHCH exhibits potent anti-proliferative effects by inducing autophagy in A549 lung cancer cells
}

\author{
GUANG-ZHOU ZHOU ${ }^{1}$, SU-LI XU ${ }^{1}$, GANG-CHUN SUN ${ }^{2}$ and XIAO-BING CHEN ${ }^{3}$ \\ ${ }^{1}$ College of Bioengineering; ${ }^{2}$ College of Chemistry and Chemical Engineering, Henan University of Technology, Zhengzhou, \\ Henan 450001; ${ }^{3}$ The Affiliated Cancer Hospital of Zhengzhou University, Zhengzhou, Henan 450008, P.R. China
}

Received October 19, 2013; Accepted March 24, 2014

DOI: $10.3892 / \mathrm{mmr} .2014 .2183$

\begin{abstract}
Curcumin is a natural polyphenolic compound that exhibits strong antioxidant and anticancer activities; however, low bioavailability has restricted its application in chemotherapeutic trials. The present study aimed to investigate the anticancer effect of the novel curcumin derivative 2E,6E-2-(1H-indol-3-yl) methylene)-6-(4-hydroxy-3-methoxy benzylidene)-cyclohexanone (IHCH) on A549 lung cancer cells. Cells were treated with $\mathrm{IHCH}$ at different concentrations (1-40 $\mu \mathrm{M})$ for different time periods (1-36 h). Microscopic analysis revealed that IHCH inhibited A549 cell growth and induced the formation of characteristic autophagolysosomes in a dose- and time-dependent manner. Furthermore, the inhibitory rate of $\mathrm{IHCH}(40 \mu \mathrm{M})$ on A 549 cell viability was $77.34 \%$ after $36 \mathrm{~h}$ of treatment. Acridine orange staining revealed an increase in autophagic vacuoles in the IHCH-treated A549 cells. Monodansylcadaverine staining was used to analyze autophagy rate. Immunocytochemistry revealed an increase in light chain (LC) 3 protein expression in the IHCH-treated cells and western blot analysis detected the conversion of LC3-I to LC3-II, as well as the recruitment of LC3 to autophagosomes in the cytoplasmatic compartment, suggesting the occurrence of autophagy. These findings show that $\mathrm{IHCH}$ induced autophagy in A549 cells, which is a novel cell death mechanism induced by curcumin derivatives.
\end{abstract}

\section{Introduction}

Autophagy is an evolutionarily conserved biological process in which under certain types of cellular stress, damaged organelles and long-lived proteins are encapsidated and

Correspondence to: Dr Guang-Zhou Zhou, College of Bioengineering, Henan University of Technology, Lianhua Street, Zhengzhou High-Tech Developmental Zone, Zhengzhou, Henan 450001, P.R. China

E-mail: gzzhou@163.com

Key words: autophagolysosomes, light chain 3, programmed cell death, synthetic analogs directed to the lysosome for degradation $(1,2)$. The cytoplasmic content is sequestered in autophagosomes, which are double-membraned vesicles that fuse with lysosomes to form autophagolysosomes, in which the cellular material is degraded by acidic lysosomal hydrolases. In addition to its physiological role in the elimination of aged or damaged cell components, autophagy acts as an important mechanism for cellular homeostasis and a survival mechanism for cells undergoing nutrient deprivation or other stresses (3). Furthermore, an increasing number of studies have shown that autophagy is involved in programmed cell death and may lead to cell death or have a cytoprotective function $(4,5)$. As an important mediator of pathological responses, autophagy has attracted increasing attention, particularly in cancer research $(6,7)$.

Curcumin is a yellow, dietary polyphenol derived from the rhizomes of Curcuma longa. Numerous studies have demonstrated that curcumin has anti-inflammatory, -oxidative and -carcinogenic effects in various types of tumor cells (8-11). However, based on its instability under certain physiological conditions, poor bioavailability and rapid metabolism, the application of curcumin in anticancer therapy has been limited (12). The generation of synthetic curcumin analogs may overcome the limitations associated with curcumin. Several studies have generated novel synthetic analogs or derivatives of curcumin in order to enhance the anti-proliferative activity of curcumin (13-15); however, such analogs have generally led to cancer cell death through apoptosis.

In the present study, a novel derivative of curcumin was chemically synthesized, termed 2E,6E-2-(1H-indol-3-yl) methylene)-6-(4-hydroxy-3-methoxy benzylidene)-cyclohexanone (IHCH) (Fig. 1). The present study aimed to investigate the cell death pathway induced by IHCH in A549 cells. IHCH was found to have an anti-proliferative effect in A549 cells by inducing autophagy. Acridine orange staining and monodansylcadaverine (MDC) fluorescence analysis were used to monitor autophagolysosomes and autophagic vacuoles, respectively. Immunocytochemistry of light chain (LC) 3 localization detected recruitment of LC3 to autophagic vesicles. Furthermore, western blot analysis was used to assess the conversion of LC3-I to LC3-II in the IHCH treated A549 cells. The present study identified that autophagy is an important process involved in IHCH-induced cell death. 


\section{Materials and methods}

Chemicals and cell culture. IHCH was obtained from the College of Chemistry and Chemical Engineering, Henan University of Technology (Zhengzhou, China) and was dissolved in dimethylsulfoxide (DMSO; stock solution, $0.1 \mathrm{M}$ ). Wortmannin was purchased from the Beyotime Institute of Biotechnology (Shanghai, China). MDC and acridine orange were purchased from Sigma-Aldrich (St. Louis, MO, USA) and fluorescein isothiocyanate (FITC)-conjugated goat anti-rabbit antibodies were purchased from Jackson ImmunoResearch Inc. (West Grove, PA, USA). A549 cells were maintained at Henan University of Technology (Zhengzhou, China) in RPMI-1640 medium (Gibco-BRL, Grand Island, NY, USA) containing $1 \%$ penicillin and $10 \%(\mathrm{v} / \mathrm{v})$ fetal bovine serum (Hyclone, Rockford, IL, USA) in a humidified atmosphere containing $5 \% \mathrm{CO}_{2}$ at $37^{\circ} \mathrm{C}$.

Cell proliferation assays. A549 cells were plated in 24-well culture plates (Corning Inc., Corning, NY, USA) and treated with $\mathrm{IHCH}$ at different concentrations $(1,5,10,20$ and $40 \mathrm{mM}$ ) for different time periods (1, 3, 6, 12, 24 and $36 \mathrm{~h})$. Cell morphology was analyzed using an inverted microscope (Nikon Eclipse TS100; Nikon Corporation, Tokyo, Japan). All experiments were repeated at least three times.

2E,6E-2-(1H-indol-3-yl) methylene)-6-(4-hydroxy-3-methoxy benzylidene)-cyclohexanone (MTT) analysis. Cells were seeded on 96-well plates and treated with IHCH at 1 , $5,10,20$ or $40 \mathrm{mM}$ for $6,12,24$ or $48 \mathrm{~h}$. MTT $(5 \mathrm{mg} / \mathrm{ml})$ was filter sterilized and added to each well $(20 \mu \mathrm{l})$. Plates were kept in the dark for $4 \mathrm{~h}$ at $37^{\circ} \mathrm{C}$ until a purple precipitate was visible. DMSO (100 $\mu \mathrm{l} /$ well) was then added and the absorbance was read using an ELISA reader (BioTek, Winooski, VT, USA) at $490 \mathrm{~nm}$. The percentage of cell viability was assessed using the following formula: Cell viability $(\%)=\left(100-A_{m} / A_{n}\right) \times 100 . A_{m}$ and $A_{n}$ represent the absorbance of the test substances and solvent control, respectively.

Acridine orange staining. Acridine orange staining was used to analyze autophagic vacuoles (16). A549 cells were treated with $\mathrm{IHCH}$ at $1,5,10,20$ or $40 \mu \mathrm{M}$ for $3,6,12$ or $24 \mathrm{~h}$. Cells were then washed twice in phosphate-buffered saline (PBS) and stained with $5 \mu \mathrm{g} / \mathrm{ml}$ acridine orange for $40 \mathrm{sec}$ at room temperature. Cell micrographs were analyzed using a fluorescence microscope (Nikon Eclipse TE2000-U; Nikon Corporation).

MDC labeling assay. Cells were seeded on 24-well flat bottomed plates over night followed by treatment with different concentrations of IHCH for $3 \mathrm{~h}$. Subsequent to treatment with hydrazinobenzoylcurcumin $(\mathrm{IHCH})$ at identical concentrations and time points, cells were incubated for 10 min with $50 \mu \mathrm{M} \mathrm{MDC}$ at $37^{\circ} \mathrm{C}$ and observed using fluorescence microscopy with a $380 \mathrm{~nm}$ excitation filter.

Immunocytochemistry analysis. Cells were seeded on coverslips in six-well plates and treated with IHCH for $3 \mathrm{~h}$. Subsequent to washing with PBS and fixing in $4 \%$

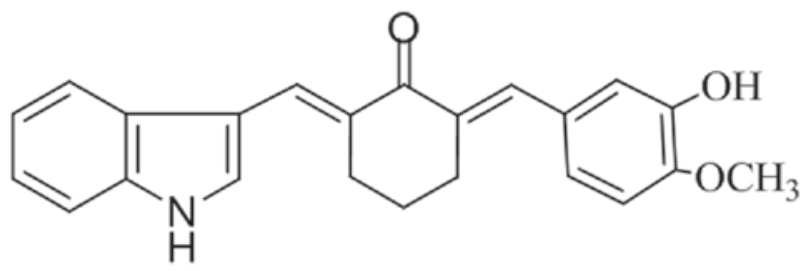

Figure 1. Chemical structure of $\mathrm{IHCH}$. The molecular formula of IHCH is $\mathrm{C}_{23} \mathrm{H}_{21} \mathrm{NO}_{3}$ and it has a molecular weight of $359.15 \mathrm{~g} / \mathrm{mol}$. IHCH, 2E,6E-2-(1H-indol-3-yl) methylene)-6-(4-hydroxy-3-methoxy benzylidene)-cyclohexanone.

paraformaldehyde for $15 \mathrm{~min}$ at room temperature, A549 cells were blocked using $5 \mathrm{mg} / \mathrm{ml}$ bovine serum albumin for $30 \mathrm{~min}$. Cells were then incubated with anti-LC3 antibodies (Beyotime Institute of Biotechnology) diluted 1:500 in PBS, followed by FITC-conjugated goat anti-rabbit antibodies diluted 1:100 in PBS for $2 \mathrm{~h}$. Slides were then analyzed using a fluorescence microscope (Nikon TE2000-U; Nikon Corporation).

Western blot analysis. A549 cells were cultured in $60 \mathrm{~mm}$ round dishes in the presence of $1,10,20$ or $40 \mu \mathrm{M}$ IHCH for $3 \mathrm{~h}$, and harvested and lysed in cold lysis buffer $(150 \mathrm{mM}$ $\mathrm{NaCl}, 1 \% \mathrm{NP}-40,20 \mathrm{mM}$ Tris- $\mathrm{HCl}, 20 \mathrm{mg} / \mathrm{ml}$ aprotinin, $20 \mathrm{mg} / \mathrm{ml}$ leupeptin, $1 \mathrm{mM}$ orthovanadate and $100 \mathrm{mM}$ phenylmethanesulfonyl fluoride, $\mathrm{pH}$ 7.4). The cell lysates were electrophoresed using 15\% SDS-PAGE and transferred to nitrocellulose membranes (Immobilon ${ }^{\mathrm{TM}}$; Millipore, Billerica, MA). Membranes were blocked with $8 \%$ non-fat dry milk in Tris-buffered saline containing Tween-20 at room temperature for $1 \mathrm{~h}$, then incubated with rabbit anti-LC3B antibodies diluted 1:1,000 in PBS, followed by alkaline phosphatase-conjugated goat anti-rabbit immunoglobulin G (Vector Laboratories Inc., Burlingame, CA, USA) diluted 1:1,000 in PBS at $4^{\circ} \mathrm{C}$ for $18 \mathrm{~h}$. Tubulin was used as an internal control. Membranes were washed and subsequently incubated with substrate solution containing nitroblue tetrazolium and bromo-4-chloro-3-indoxyl-phosphate (Boster Biological Technology, Ltd., Wuhan, China). Image J (National Institutes of Health, Bethesda, MA, USA) was used to quantify the intensity of each protein band. Band intensity values were presented as the fold increase or decrease with respect to the control bands.

Statistical analysis. Experiments were performed three times and data are presented as the mean \pm standard deviation. Differences between mean values were analyzed using Student's t-test. $\mathrm{P}<0.05$ or $<0.01$ were considered to indicate statistically significant differences.

\section{Results}

IHCH inhibits A549 cell proliferation. A549 cells were treated with different concentrations of IHCH $(1-40 \mu \mathrm{M})$ for $36 \mathrm{~h}$. DMSO was used as a negative control. After $3 \mathrm{~h}$, the IHCH-treated cells exhibited vacuole-like structures. Furthermore, significant changes were observed in cell morphology after $6 \mathrm{~h}$ of IHCH treatment (Fig. 2A). MTT was 
A

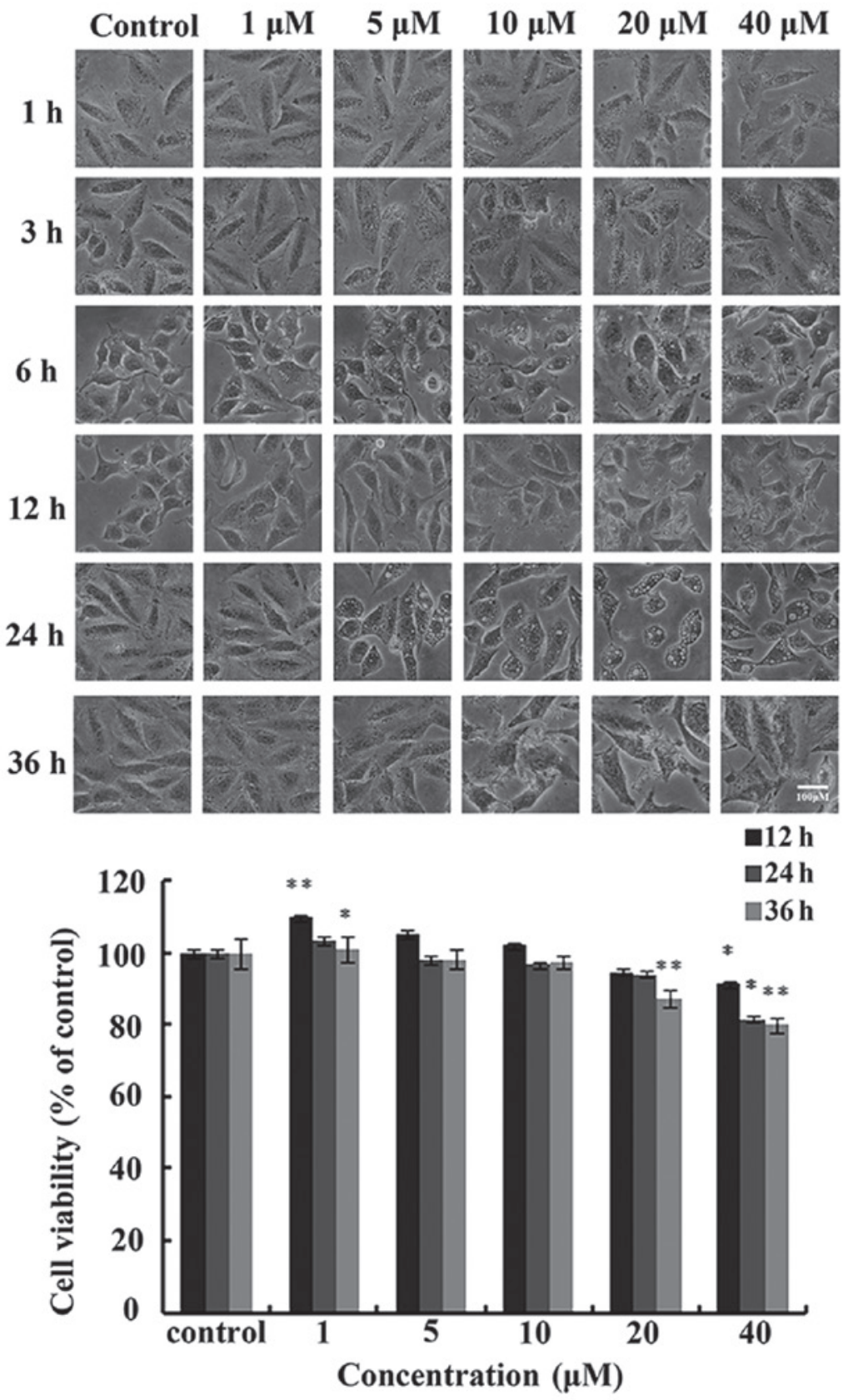

Figure 2. Effect of IHCH treatment on A549 cell morphology. (A) IHCH-treated A549 cells at different concentrations and time points. (B) Proliferative activity of A549 cells assessed using an 2E,6E-2-(1H-indol-3-yl) methylene)-6-(4-hydroxy-3-methoxy benzylidene)-cyclohexanone assay. IHCH (40 $\mu \mathrm{M})$ significantly inhibited the proliferation of A549 cells. Values are presented as the mean \pm standard error of at least three independent experiements. ${ }^{*} \mathrm{P}<0.05$ and ${ }^{* *} \mathrm{P}<0.01$ vs. control (n=5). IHCH, 2E,6E-2-(1H-indol-3-yl) methylene)-6-(4-hydroxy-3-methoxy benzylidene)-cyclohexanone.

used to assess the effect of IHCH on A549 cell viability and showed that cell viability was reduced to $77.34 \%$ after $36 \mathrm{~h}$ of treatment with $40 \mu \mathrm{M}$ IHCH (Fig. 2B).

IHCH induces the formation of acidic vesicular organelles (AVOs) in A549 cells. Autophagolysosomes generate an acidic compartment, which may be fluorescently stained red or green using acridine orange (17). To determine whether IHCH induced autophagy in A549 cells, acridine orange staining was performed in IHCH-treated A549 cells. Autophagy is associated with an increase in acridine orange positive AVOs. Red AVOs were observed following $3 \mathrm{~h}$ of $\mathrm{IHCH}$ treatment (1-40 $\mu \mathrm{M})$ in the A549 cells (Fig. 3A), suggesting AVO formation. Furthermore, the percentage of cells exhibiting AVOs was analyzed among $100 \mathrm{IHCH}$-treated cells. After $3 \mathrm{~h}$ of IHCH treatment, the percentage of cells with AVOs was found to increase in a concentration-dependent manner (1-20 $\mu \mathrm{M})$ (Fig. 3B).

Wortmannin inhibits IHCH-induced A549 cell autophagy. As a specific dye for autophagosomes, MDC accumulates in mature autophagic vacuoles (AVs) and autophagolysosomes, but not in the early endosome compartment. In the present study, MDC-stained AVs appeared as distinct dot-like structures distributed within the cytoplasm or localized in the perinuclear region. Furthermore, the highest number 
A
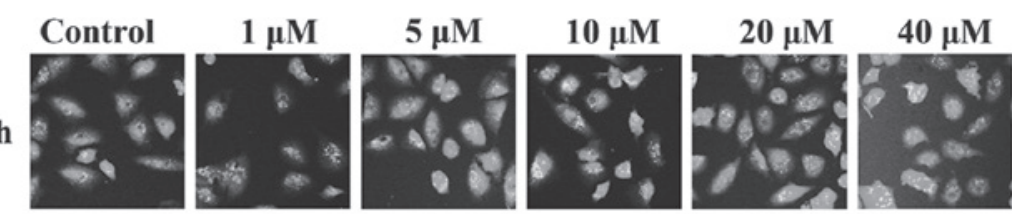

$3 \mathbf{h}$
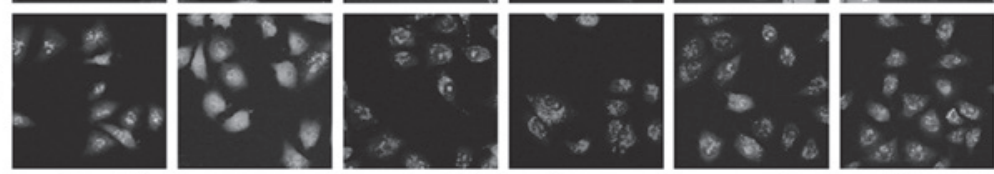

$6 \mathrm{~h}$
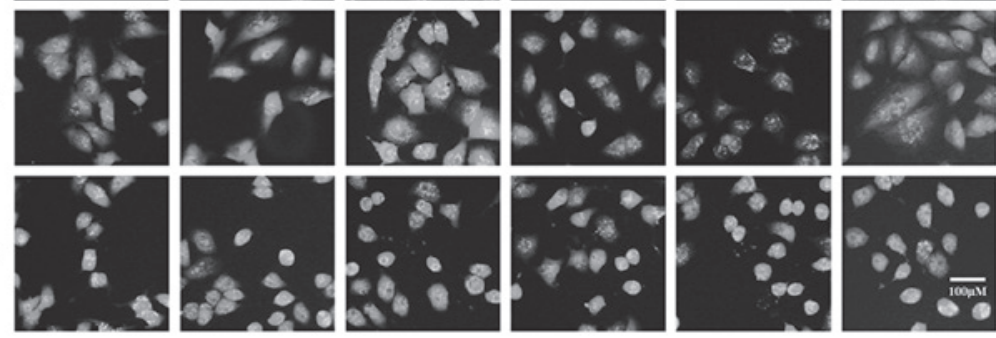

B

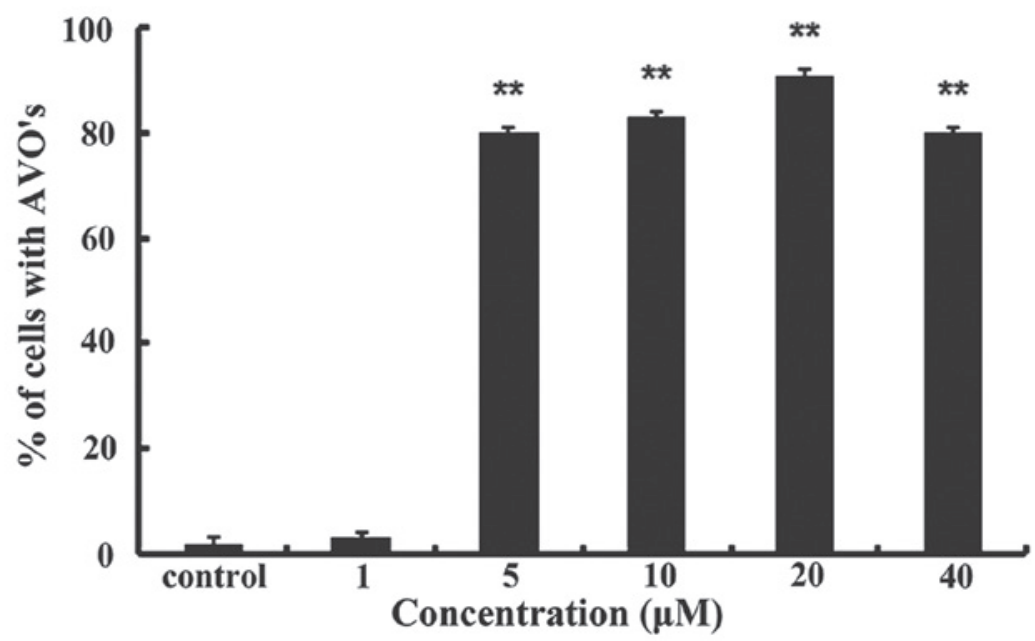

Figure 3. Detection of AVOs in IHCH-treated A549 cells using fluorescence microscopy. (A) Cells were incubated with various concentrations of IHCH for different durations and stained with acridine orange. (B) Percentage of cells exhibiting AVOs following treatment with different concentrations of IHCH. A total of 100 cells were counted in more than three, randomly selected fields of view. Data are presented as the mean \pm standard error of triplicate experiments. ${ }^{* *} \mathrm{P}<0.01$ vs. control. IHCH, 2E,6E-2-(1H-indol-3-yl) methylene)-6-(4-hydroxy-3-methoxy benzylidene)-cyclohexanone; AVOs, acidic vesicular organelles.

of dot-like structures were observed after $3 \mathrm{~h}$ of treatment with $20 \mu \mathrm{M}$ IHCH (Fig. 4A). Wortmannin was also used to treat the IHCH-incubated A549 cells. As a highly specific inhibitor of phosphatidylinositol-4,5-bisphosphate 3-kinase, wortmannin is capable of inhibiting the Akt signaling pathway and cell autophagy (18). In the present study, wortmannin was found to decrease the intensity of the MDC fluorescence at the different concentrations of $\mathrm{IHCH}$ (Fig. 4A). Furthermore, the rate of cell autophagy following wortmannin treatment was observed to be lower than that in the untreated cells (Fig. 4B).

IHCH induces LC3 protein accumulation. The intracellular localization of the LC3 protein was analyzed using immunocytochemistry. IHCH-treated $(20 \mu \mathrm{M} ; 3$ h) A549 cells were immunostained using anti-LC3 primary antibodies. Fluorescence microscopy revealed that the specific fluorescent signals were punctate, which is typical of the distribution of LC3-II within autophagosomes (Fig. 5). The DMSO-treated control cells showed no LC3 immunofluorescence.
IHCH induces the conversion of LC3-I to LC3-II. Western blot analysis was used to detect LC3-II and -I, with increases in the LC3-II/LC3-I ratio indicative of autophagy (19). Lysates of A549 cells treated with DMSO $(40 \mu \mathrm{M})$ or IHCH $(1-40 \mu \mathrm{M})$ for $3 \mathrm{~h}$ were subjected to western blot analysis. Fig. 6A shows the conversion of LC3-I to LC3-II. The level of autophagy was represented as the ratio of LC3-II expression to tubulin expression (Fig. 6B). LC3-II protein expression was observed to significantly increase in the IHCH-treated cells in a dose-dependent manner. This finding suggests IHCH induced autophagy in the A549 cells.

\section{Discussion}

A number of bioactive compounds are phytochemicals, which have been found to demonstrate growth suppressive activity as well as chemopreventive properties against various types of cancer (20). One of the most widely characterized phytochemicals is curcumin, whose inhibitory effects on tumorigenesis and tumor growth have been confirmed in vitro 
A

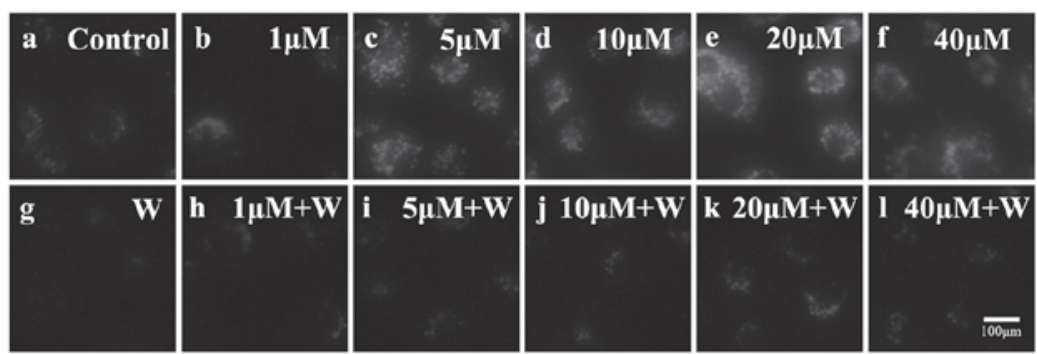

$\mathbf{B}$

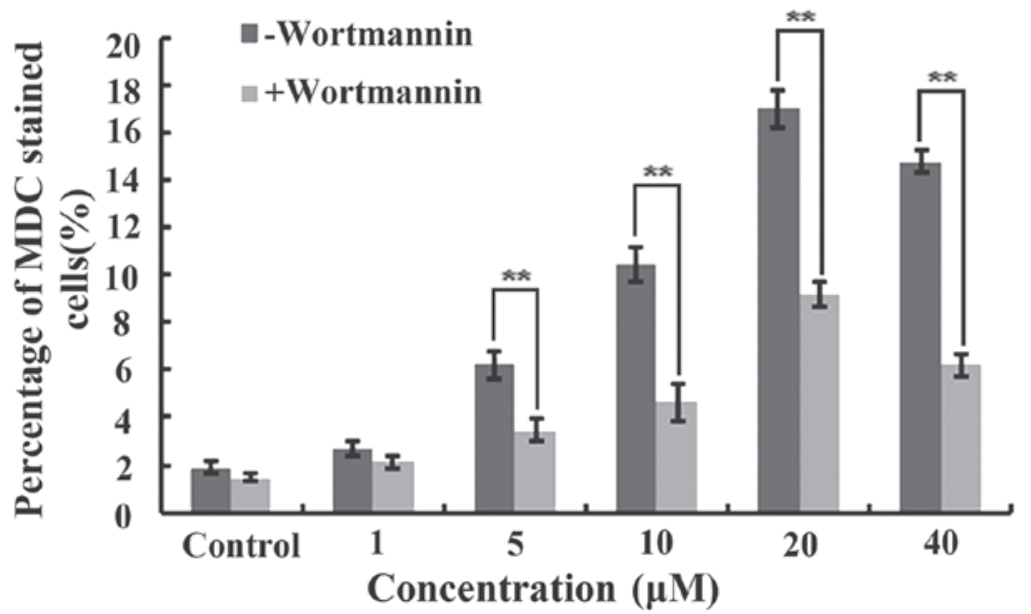

Figure 4. MDC labeling of IHCH-treated A549 cells. (Aa-f) Fluorescence microscopy of MDC-stained punctuate autophagosomes; (Ag-1) wortmannin (100 nM) inhibited the formation of autophagosomes detected using MDC staining. (B) Statistical analysis of the rate of autophagy in A549 cells based on MDC staining. Data are presented as the mean \pm standard error of 10 fields of view. ${ }^{* *} \mathrm{P}<0.01$ vs. control. IHCH, 2E,6E-2-(1H-indol-3-yl) methylene)-6-(4-hydroxy-3-methoxy benzylidene)-cyclohexanone; MDC, monodansylcadaverine.
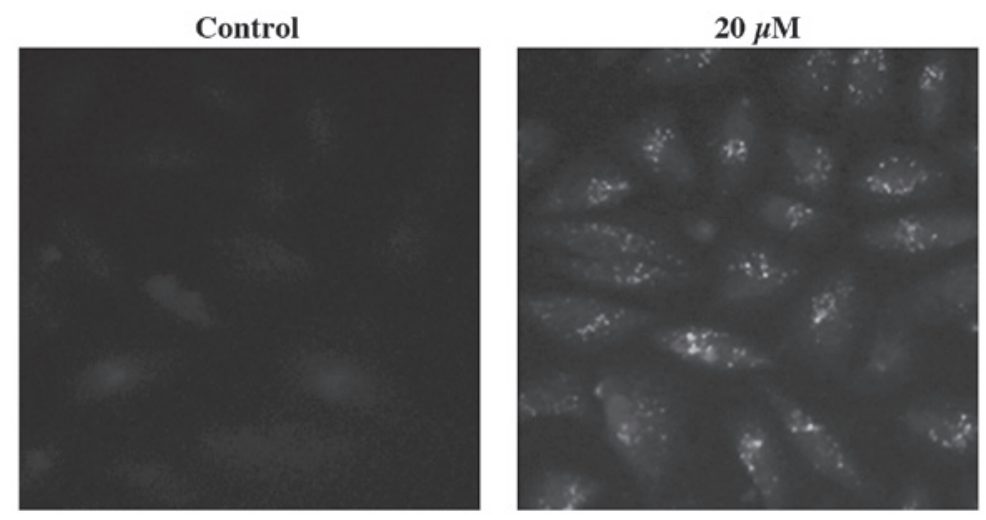

Figure 5. Immunofluoresence of LC3 in IHCH-treated A549 cells. Treatment with $20 \mu \mathrm{M}$ IHCH induced punctate LC3 expression. Control cells were treated with dimethylsulfoxide. Magnification, x400. IHCH, 2E,6E-2-(1H-indol-3-yl) methylene)-6-(4-hydroxy-3-methoxy benzylidene)-cyclohexanone; LC3, light chain 3.

A

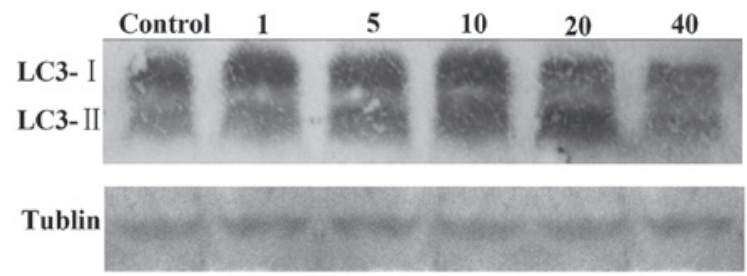

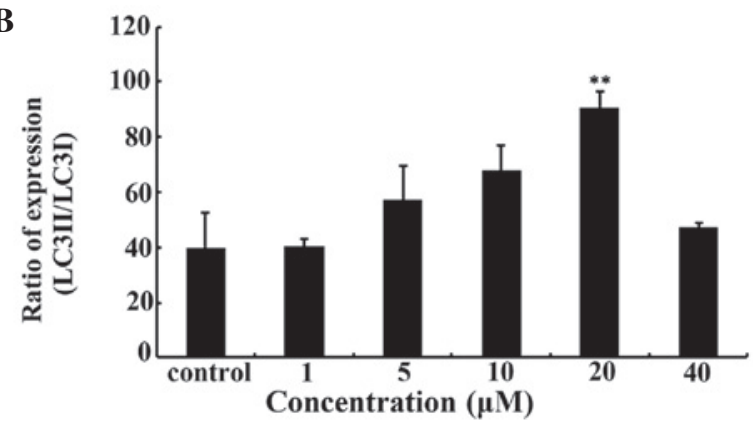

Figure 6. (A) Conversion of LC3-I to LC3-II in IHCH-treated A549 cells. A549 cells were exposed to IHCH (1-40 $\mu \mathrm{M})$ for $3 \mathrm{~h}$. Tubulin was used as a loading control. (B) Ratio of LC3-II/LC3-I expression in IHCH-treated A549 cells $(\mathrm{n}=3)$. ${ }^{* *} \mathrm{P}<0.01$ vs. control. IHCH, 2E,6E-2-(1H-indol-3-yl) methylene)-6-(4-hydroxy-3-methoxy benzylidene)-cyclohexanone; LC3, light chain 3. 
and in vivo (21). Due to the low bioavailability of curcumin, curcumin alternatives have been investigated. In our previous study, an analog of curcumin, HBC, was chemically synthesized and its inhibitory effect on A549 lung cancer cells was identified (22).

In the present study, an MTT assay revealed that $40 \mu \mathrm{MIHCH}$ inhibited cell proliferation after $36 \mathrm{~h}$. In order to investigate the cell death mechanism associated with this IHCH-induced decrease in cell proliferation, IHCH-treated A549 cells were subjected to acridine orange and MDC staining, as well as immunofluorescent and western blot analyses. Acridine orange staining revealed a concentration-dependent increase in red fluorescent structures after $3 \mathrm{~h}$ of IHCH treatment. However, the red fluorescence in the A549 cells was found to decrease with increasing $\mathrm{IHCH}$ treatment duration. Thus, all subsequent experiments were performed using A549 cells treated with $\mathrm{IHCH}$ for $3 \mathrm{~h}$. MDC staining revealed a concentration-dependent increase in fluorescent structures in the IHCH-treated A549 cells, which was inhibited upon pretreatment with wortmannin $(100 \mathrm{nM})$. Wortmannin is a typical inhibitor of autophagy (18). These findings suggest that IHCH may lead to A549 cell death through inducing autophagy.

As a key marker of cell autophagy, LC3 is associated with autophagosome expression. In order to investigate whether IHCH induces A549 cell autophagy, immunofluoresence and western blot analyses of LC3 protein expression were performed. Immunofluorescence revealed punctate accumulation of LC3 in the cytoplasm of A549 cells in response to IHCH. Furthermore, western blot analysis showed a dose-dependent increase of LC3-II expression in IHCH-treated A549 cells. These findings show that IHCH induces A549 cell death through autophagy; however, the specific autophagy pathway involved requires further investigation. The present study has shown that IHCH may have potential as a therapeutic, anti-proliferative agent in cancer.

\section{Acknowledgements}

This study was supported by grants from the National Natural Science Foundation of China (grant nos. 31101931 and 81172240), the High-Level Talents Fund from Henan University of Technology (grant no. 2010BS016) and the Plan for Scientific Innovation Talent of Henan University of Technology (grant no. 11CXRC13).

\section{References}

1. Levine B and Kroemer G: Autophagy in the pathogenesis of disease. Cell 132: 27-42, 2008.

2. Mizushima N, Levine B, Cuervo AM and Klionsky DJ: Autophagy fights disease through cellular self-digestion. Nature 451: 1069-1075, 2008.

3. Schiøtz BL, Roos N, Rishovd AL and Gjøen T: Formation of autophagosomes and redistribution of LC3 upon in vitro infection with infectious salmon anemia virus. Virus Res 151: 104-107, 2010.
4. Maiuri MC, Zalckvar E, Kimchi A and Kroemer G: Self-eating and self-killing: crosstalk between autophagy and apoptosis. Nat Rev Mol Cell Biol 8: 741-752, 2007.

5. Eisenberg-Lerner A, Bialik S, Simon HU and Kimchi A: Life and death partners: apoptosis, autophagy and the cross-talk between them. Cell Death Differ 16: 966-975, 2009.

6. Gurusamy N and Das DK: Autophagy, redox signaling, and ventricular remodeling. Antioxid Redox Signal 11: 1975-1988, 2009.

7. Wang Q, Liang B, Shirwany NA and Zou MH: 2-Deoxy-D-glucose treatment of endothelial cell induces autophagy by reactive oxygen species-mediated activation of the AMP-activated protein kinase. PLoS One 6: e17234, 2011.

8. Chang PY, Peng SF, Lee CY, et al: Curcumin-loaded nanoparticles induce apoptotic cell death through regulation of the function of MDR1 and reactive oxygen species in cisplatin-resistant CAR human oral cancer cells. Int J Oncol 43: 1141-1150, 2013.

9. Norris L, Karmokar A, Howells L, Steward WP, Gescher A and Brown K: The role of cancer stem cells in the anti-carcinogenicity of curcumin. Mol Nutr Food Res 57: 1630-1637, 2013

10. Ranjan AP, Mukerjee A, Helson L, Gupta R, Vishwanatha JK: Efficacy of liposomal curcumin in a human pancreatic tumor xenograft model: inhibition of tumor growth and angiogenesis. Anticancer Res 33: 3603-3609, 2013.

11. Doggui S, Belkacemi A, Paka GD, Perrotte M, Pi R and Ramassamy C: Curcumin protects neuronal-like cells against acrolein by restoring Akt and redox signaling pathways. Mol Nutr Food Res 57: 1660-1670, 2013.

12. Anand P, Kunnumakkara AB, Newman RA and Aggarwal BB: Bioavailability of curcumin: problems and promises. Mol Pharm 4: 807-818, 2007.

13. Kumaravel M, Sankar P and Rukkumani R: Antiproliferative effect of an analog of curcumin bis-1,7-(2-hydroxyphenyl)-he pta-1,6-diene-3,5-dione in human breast cancer cells. Eur Rev Med Pharmacol Sci 16: 1900-1907, 2012.

14. Xiao J, Wang Y, Peng J, et al: A synthetic compound, 1,5-bis(2-methoxyphenyl)penta-1,4-dien-3-one (B63), induces apoptosis and activates endoplasmic reticulum stress in non-small cell lung cancer cells. Int J Cancer 131: 1455-1465, 2012.

15. Faião-Flores F, Suarez JA, Maria-Engler SS, Soto-Cerrato V, Pérez-Tomás R and Maria DA: The curcumin analog DM-1 induces apoptotic cell death in melanoma. Tumor Biol 34: $1119-1129,2013$.

16. Arsikin K, Kravic-Stevovic T, Jovanovic M, et al: Autophagy-dependent and -independent involvement of AMP-activated protein kinase in 6-hydroxydopamine toxicity to SH-SY5Y neuroblastoma cells. Biochim Biophys Acta 1822: 1826-1836, 2012

17. Paglin S, Hollister T, Delohery T, et al: A novel response of cancer cells to radiation involves autophagy and formation of acidic vesicles. Cancer Res 61: 439-444, 2001.

18. Buchanan CM, Dickson JM, Lee WJ, Guthridge MA, Kendall JD and Shepherd PR: Oncogenic mutations of p110a isoform of PI 3-kinase upregulate its protein kinase activity. PLoS One 8: e71337, 2013.

19. Kabeya Y, Mizushima N, Yamamoto A, Oshitani-Okamoto S, Ohsumi Y and Yoshimori T: LC3, GABARAP and GATE16 localize to autophagosomal membrane depending on form-II formation. J Cell Sci 117: 2805-2812, 2004.

20. Aggarwal BB and Shishodia S: Molecular targets of dietary agents for prevention and therapy of cancer. Biochem Pharmacol 71: 1397-1421, 2006.

21. Kunnumakkara AB, Anand P and Aggarwal BB: Curcumin inhibits proliferation, invasion, angiogenesis and metastasis of different cancers through interaction with multiple cell signaling proteins. Cancer Lett 269: 199-225, 2008.

22. Zhou GZ, Zhang SN, Zhang L, Sun GC and Chen XB: A synthetic curcumin derivative hydrazinobenzoylcurcumin induces autophagy in A549 lung cancer cells. Pharm Biol 52: 111-116, 2014. 